\title{
A Game Theoretic Study of Enterprise Mergers and Acquisitions: The Case of RJR Nabisco Being Acquired by KKR
}

\author{
Yanqing Jiang ${ }^{1}$, Jian Yuan ${ }^{1}$, Mengmeng Zeng ${ }^{1}$ \\ ${ }^{1}$ School of Economics and Finance, Shanghai International Studies University, China \\ Correspondence: Yanqing Jiang, School of Economics and Finance, Shanghai International Studies University, No. \\ 1550 Wenxiang Rd., Shanghai 201620, P. R. China.
}

Received: April 15, 2016 Accepted: April 30, 2016 Online Published: May 9, 2016

doi:10.11114/bms.v2i2.1552 URL: http://dx.doi.org/10.11114/bms.v2i2.1552

\begin{abstract}
There are both macro- and micro-level studies concerning enterprise mergers and acquisitions (M\&A). Past studies have focused on M\&A valuation, utility of the M\&A motives and the strategic behavior during of the M\&A process. Few game theory methods in the application of M\&A stay mostly in the analysis of Nash equilibrium under the complete information static game. This paper thus aims to analyze the M\&A behavior of enterprises within the framework of incomplete information dynamic game, combined with sub-game perfect Nash equilibrium of complete information dynamic game and Bayesian Nash equilibrium of incomplete information.
\end{abstract}

Keywords: merger \& acquisition, game, stakeholder, KKR

\section{Introduction}

There are two main ways for enterprises to grow, of which one is by continuous production expansion contingent on internal operating reinvestment, and the other is by merger and reorganization under external capital market forces. In fact, Nobel prize-winning economist Stigler once argued that no big enterprises in the U.S. grew up without M\&A (mergers and acquisitions) and very few enterprises mainly relied on internal expansion for growth (Stigler, 1996). From a historical point of view, home and abroad, M\&A often occur in phases of technology revolution, business cycle rotation, enterprise strategic shift, and policy relaxation. Currently, the Chinese M\&A market meets a good timing of economic restructuring, technological progress, and policy relaxation, combined with the emergence of new market intermediaries including industrial M\&A funds and bonds. All these tend to indicate that there will be a historic boom of the Chinese M\&A market (See Figure 1 for example). Since 2014, the Chinese economy has exhibited the "New Normal" characteristics and has gone into a steady growth stage with a moderate growth speed. M\&A play an important role in promoting the growth of capital market platforms and accelerating structural adjustments. A time of structural transition is one where M\&A events would mushroom. First, merger, acquisition and reorganization are effective means to solve the problem of excess production capacity. According to the Tobin $\mathrm{Q}$ theory, via the process of high-Q-value enterprises acquiring low-Q-value ones, we aim to realize the return of the overall Q level, which may have certain effects in reducing total output of the industry. Second, we can allow new industries to develop and create new growth points by merger, acquisition and reorganization. On the one hand, through M\&A, the enterprises in the field of emerging industries are expected to realize the integration of the industrial chain, improve product competitiveness, and accelerate the shift from product competition to industry competition. On the other hand, encouraging the traditional enterprises to transfer to service industries through $M \& A$ is helpful for enlarging the proportion of the tertiary industry in the national economy, which in turn helps promote the upgrading of the industrial structure in China. What deserves to be mentioned the most is that China has always been following the development path of economic reform, and one important direction of the reform is to promote overall listing of state-owned enterprises. The introduction of social capital (private capital, foreign capital, etc.) is to realize a mixed ownership.

Looking back into the past 38 years' history of the reform of the state-owned enterprises, we can clearly see a logical line, namely, that the reform of the state-owned enterprises has always revolved around the connections between the government, the state-owned enterprises and the market. However, the game played between the local government, the central government and the private capital often leads to considerable difficulty in achieving equilibrium and integration. 


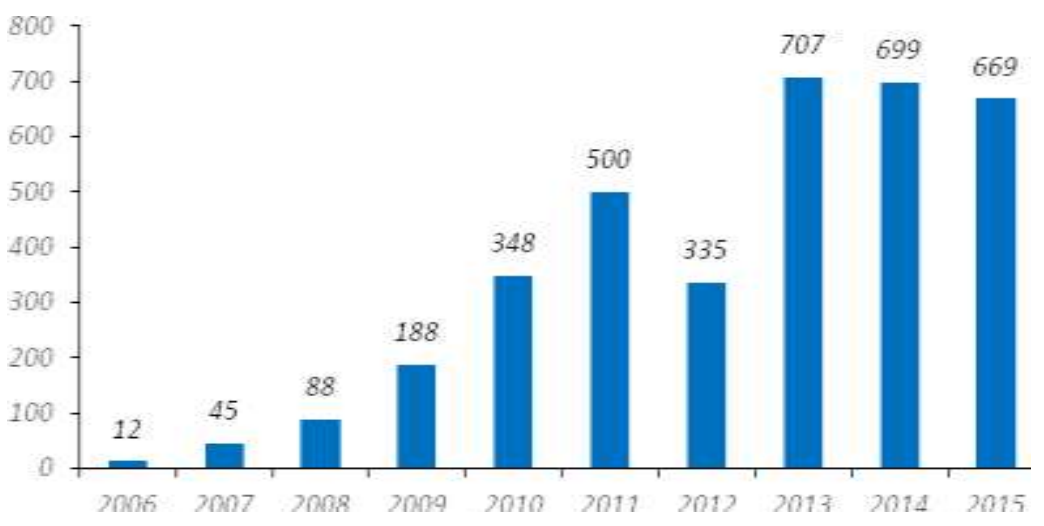

Figure 1. The Times of Chinese M\&A 2006-2015

(Data Source: Qingke Database)

\section{Studies on M\&A}

Studies on M\&A may focus either on the macro level or the micro level. Macro level analysis is mainly concerned with the relationship between GNP, various kinds of price indices and the overall level of the M\&A market. In contrast, there are mainly two sublevels in micro level analysis, of which one is concerned with the behavioral analysis about enterprise M\&A motives and M\&A performances, and the other is concerned with the driving factors upon both sides of the M\&A enterprises in the capital market, and the effect analysis of the M\&A mechanism on the reallocation of resources, etc. However, both the macro- and micro level analysis eventually traces back to the analysis of the microstructure, as the M\&A research objective is on the enterprise, and the research fundamentally aims to analyze the problem of individual enterprise's utility maximization, output maximization, cost minimization or profit maximization (Andrade, Mitchell, and Stafford, 2001). Thus the M\&A decision is finally a microeconomic decision. M\&A can be divided into three categories by type. Horizontal M\&A motivation is mainly concerned with economies of scale, vertical M\&A is mainly associated with vertical integration for saving transaction costs, and mixed M\&A is concerned with the enterprise's strategy for product diversification (Perry and Porter, 1985). In sum, theories for M\&A include the management synergy theory, the different efficiency theory, the scale economy theory, the scale effect hypothesis, the portfolio theory, the diversification strategy theory, the financial synergy theory, the tax avoidance hypothesis, the speculation theory, the undervalued hypothesis, the market competition theory, the market power hypothesis, the transaction cost theory, the organization-substituting-the-market hypothesis, etc. After careful consideration, we can see that the process of M\&A can be cut into three slices. The first slice is the self-evaluation of the target enterprise, the second slice is the assessment of the value of the target enterprise by the acquirer, and the third slice is the game process played between the acquirer and the target enterprise. The both sides come close in the evaluation method of the value assessment while the difference lies in the information each side has about the target enterprise value as well as in the valuation procedure each side (which is in favor of its own interests) adopts in making accounting decisions (Leland, 2007). Valuation and profit forecast fall into a field where relevant financial research is quite abundant. Regarding the third slice, theoretical research (as well as related case studies) in this area is scanty. Our study in the present paper is one of the few attempts ever to investigate the issue of M\&A from a game theoretic perspective. In the following section, we present a summary of the application of the game theory in enterprise M\&A.

\section{The Game Theory and Enterprise M\&A}

Investors, shareholders, the management, local governments, creditors and intermediary institutions, etc., are all involved in the process of enterprise M\&A. It is well known in the game theory that rational behavior of rational people can lead to collective irrationality, which gives rise to the argument that the solution to the conflict between individual rationality and collective rationality does not lie in the denying of individual rationality, but instead in the designing of a mechanism in order to reach collective rationality based on individual rationality. Economic research usually prefers individual decision makers to be its research objects and avoids assumptions with no micro foundation. Starting from the individual utility function and the constraint conditions, the analysis finds out the solution to the individual utility maximization problem under the constraint conditions and reaches the result of the equilibrium situation (Zhang, 1996). This procedure is in line with the game theory research paradigm.

Using the basic methodology of the game theory, some scholars put forward the argument that the key to the success of enterprise M\&A is whether the M\&A stakeholders' interests reach an effective equilibrium (Hong, 2001). Take the example in which state-owned enterprises intake private capital. The stakeholders of all parties (shareholders, the 
management, creditors of private capital, the local district government of private capital, the investment banks, etc.) in the M\&A are involved in a game among themselves and in a game with target enterprise stakeholders (the local government, the state-owned enterprise management, the investment banks, etc.) In addition, the specific form (cash, assets or shares exchange, etc.) and pricing (undervalued or overvalued, how much loss or premium of state-owned assets, etc.) of the M\&A are related to whether the interests of stakeholders have achieved effective equilibrium. Considering the situation that with each additional game player, the game design will become progressively complex, we divide the stakeholders into two camps, namely A (the acquirer group) and B (the target enterprise group). By doing so the game is simplified to a two sides' game. M\&A games in real life are dynamic rather than static, and the information players have is incomplete and asymmetric (Nogeste, 2010). Existing studies mostly stay with complete information static one-time game to find the Nash equilibrium solution. This paper expands the scenario to incomplete information dynamic game analysis, based on complete information static game (Table 1).

Table 1. The Classification of the Game

\begin{tabular}{lll}
\hline & Static state & Dynamic state \\
\hline $\begin{array}{l}\text { Complete } \\
\text { information }\end{array}$ & Complete information static game & Complete information dynamic \\
& Nash equilibrium & Same \\
& Nash (1950,1951) & Selten (1965) \\
Incomplete & Incomplete information static state & Incomplete information dynamic \\
information & game & game \\
& Bayesian Nash equilibrium & Perfect Bayesian Nash equilibrium \\
& Harsanyi (1967-1968) & Selten (1975)
\end{tabular}

The following (Table 2) is the most typical static game analysis paradigm, with game subjects (acquirer A and target enterprise B), the strategies (A's strategy is bona fide acquisition or hostile acquisition, B's strategy is to accept or reject), and payoff function (respective benefits Aij and Bij under different situations). This kind of analysis must be based on the hypothesis that full information has been disclosed, both sides in the M\&A are rational people, each player fully understands the strategies and payoffs and decisions are made at the same time (Gan, 2005). This can be considered as an extreme situation.

Table 2. Complete Information Static Game

\begin{tabular}{llll}
\hline & & \multicolumn{2}{c}{ Target enterprise B } \\
\cline { 3 - 4 } & & Accept & Reject \\
Fcquirer A & $\begin{array}{l}\text { Friendly } \\
\text { acquisition } \\
\text { Hostile }\end{array}$ & (A11, B11) & (A12, B12) \\
acquisition & $($ A21, B21) & $($ A22, B22) \\
& &
\end{tabular}

In real cases of $\mathrm{M} \& \mathrm{~A}$, acquirers and target enterprises tend to finalize purchase price after more than one round of "battle". Both sides go through a round of negotiations of offer - bargain - offer - bargain -...- accept the final price (Smit and Akum, 1993). That is, most real M\&A games are repeated game model of game tree as below (Figure 2). Acquirer's highest offer is P1, Target enterprise's lowest offer is $\mathrm{P} 2$, the equilibrium price is $\mathrm{P} *$, acquirer gives an offer for the ith time, target enterprise gives a bargaining for the ith time, if the game can go on repeatedly, it usually meet the condition of $\mathrm{P} 2<\mathrm{Vi}<\mathrm{P}^{*}<\mu \mathrm{i}<\mathrm{P} 1$. Assuming that $\mathrm{V} 1<\mathrm{P} 2$, it means that acquirer's first offer is much lower than target enterprise's lowest offer. According to this information, target enterprise can figure out that this acquirer's intention is not sincere and then refuse the acquirer's offer to end the game. Also, when $\mathrm{P} 2<\mathrm{V} 1$, if $\mathrm{P} 1<\mu 1$, which indicates that target enterprise's bargaining is far higher than acquirer's affordable highest price, acquirer will give up offer according to this feedback information from target enterprise. Therefore, here we clarify the dynamic game method of bargaining, the essence of M\&A is both sides make valuation for the target enterprise based on their information respectively and reach the game equilibrium price $\mathrm{P} *$ according to each other's feedback and relative power (Cao and Yang, 2005). Acquirer's highest offer P1 is a price when acquirer's net income is zero after M\&A, target enterprise's lowest offer P2 is a price when target enterprise's net income is zero after M\&A. The unit net income after M\&A is P1-P2. The essential purpose of M\&A is to carve up this spilled part. Eventual equilibrium price $\mathrm{P} *$ depends on the relative power of both sides. Relative forces are not quantitative, because both sides' bargaining power depends on acquirer forces (acquirer's market competitiveness, master of information, desire for the target enterprise, etc.) and target enterprise forces (target 
enterprise's operation status, information advantage, equity structure, etc.) (Binmore, Ariel, and Wolinsky, 1986).

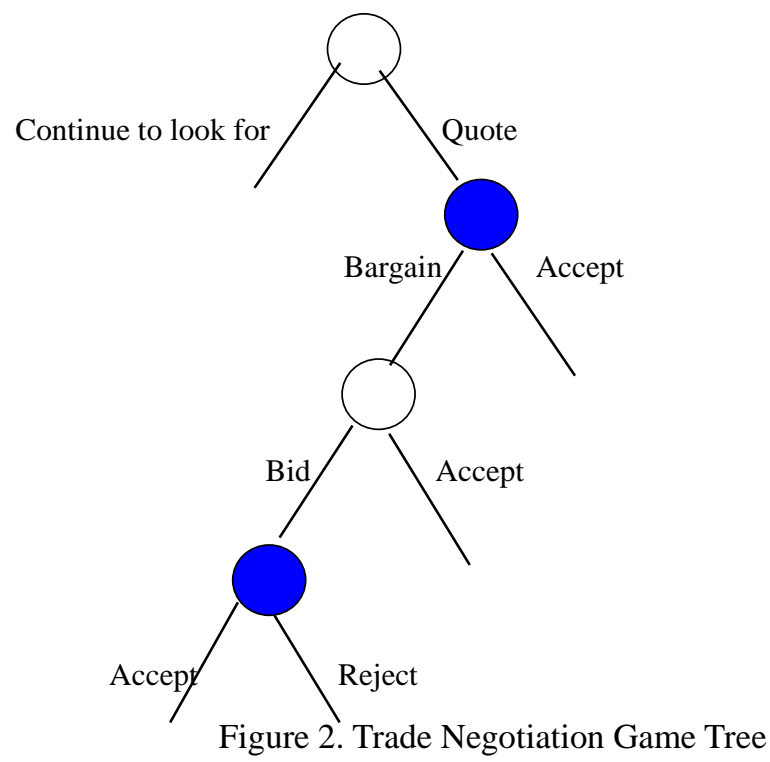

Seeing either static or dynamic game is conducted under the situation of perfect information, we then need to put the game into a more realistic situation, namely the game under incomplete information. Acquisition offer will be based on their own judgment for target enterprise (asset quality, operation condition, strategic value, financial structure, etc.), which to a large extent depends on target enterprise's historical information disclosure (Fang, 2002). In other words, acquirer knows that target enterprise is in high yield $\theta_{1}$ with the probability $\mathrm{P}$ and in low yield $\theta_{2}$ with the probability of 1 - P, the judge here is based on the prior probability $\mathrm{P}$. To be sure, in the game, the acquirer can know the target enterprise is in cooperation or not, namely (as shown in figure 3) the information acquirer can grasp is just one combination of target enterprise connected by the dotted line below (cooperation is X3 and X5, no cooperation is X4 or $\mathrm{X6}$ ), the acquirer does not know the signal is from the $\mathrm{X} 1$ node or $\mathrm{X} 2$ node, namely acquirer can judge the probability that enterprise is in $\theta_{1}$ or $\theta_{2}$, but cannot accurately obtain the information of enterprise condition just from cooperation or non-cooperation (for acquirer, investment decisions and subsequent earnings expectations of the target enterprise are uncertain).Finally, even acquirer determines to buy the target enterprise, its offer is clearly based on target enterprise quality level $\theta$, but $\theta$ complies with a certain probability distribution $\mathrm{P}(\theta)$. As a result, the final quotation is associated with $\mathrm{P}(\theta)$. The point of the dynamic game lies in seeing whether the participant can observe the opponent's actions (the signals) to verify the prior probability and continually correct previous assumptions to approach true assessment of target enterprise according to posterior probability (Jarrell and Poulsen, 1989). 


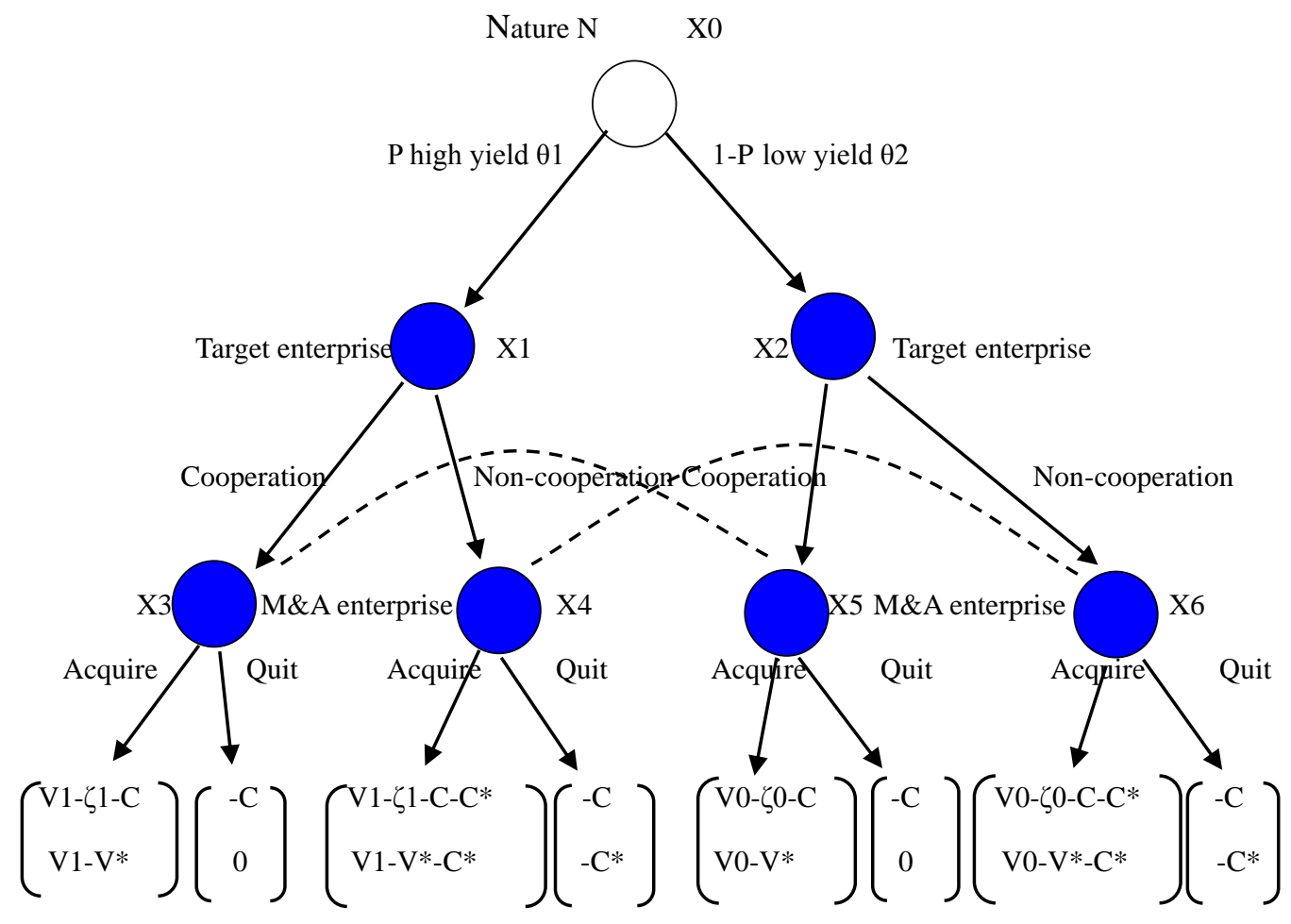

Figure 3. Incomplete Information Dynamic Game Structure

In complete information static game application, Nash equilibrium can solve many problems. Dynamic game can also reach Nash equilibrium by application of backward induction method. And in the condition of incomplete information dynamic game, incomplete information problem needs to be solved by choice at a certain probability through Harsanyi transformation, such as the natural condition $\mathrm{N}$ set in the figure above, then it makes choice about the quality of the target enterprise $\theta$ with probability $\mathrm{P}(\theta)$, by Harsanyi transformation, incomplete information dynamic game becomes an extended analysis of a complete but imperfect information (known about the distribution probability while not known about specific type). Incomplete information dynamic game is the combination of sub-game refining Nash equilibrium of complete information dynamic game with incomplete information static equilibrium of Bayesian Nash equilibrium. We can assume that if the acquirer regarded the target enterprise as high quality enterprise, its offer is $\zeta 1$, and $\zeta 0$ for low quality. According to the prior probability P, acquirer judges that the target enterprise's potential value is $\mathrm{V} 1$ when being in a state of high yield, the probability of $1-\mathrm{P}$ is in a state of low yield when the target enterprise's potential value is $\mathrm{V} 0$. The target enterprise sets its own value evaluation as $\mathrm{V}^{*}$, meanwhile the acquirer pays fixed costs C. If the target enterprise chooses to be cooperative, its cost can be set as 0 . But if the target enterprise chooses to be anti-takeover, its cost can be $\mathrm{C}^{*}$. Thus we can get the payoff matrix under different situations, such as the matrix in the figure above. Its first row is acquirer's payoff function, the second row is target enterprise's payoff function. According to the conditional probability of Bayesian transformation, we can calculate the expected return of acquirer and target enterprise under all kinds of strategies. Making a comparison in the payoffs of strategic matrix under X3 node, we can find that $\mathrm{V} 1-\zeta 1-\mathrm{C}>-\mathrm{C}$ (rational acquirer's valuation $\mathrm{V} 1>$ offer $\zeta 1$ ), then the acquirer will choose to buy it when the target enterprise is cooperative. The game analysis under X5 node is same with that. Further comparing the strategic choices of X4 and X6 nodes, analyzing the relationship between $\mathrm{V} 1-\zeta 1-\mathrm{C}-\mathrm{C} *$ and $\mathrm{C} *$ to see if $\mathrm{V} 1-\zeta 1-\mathrm{C}>0$. Here we cannot judge whether the overflow V1- $\zeta 1$ of acquirer is greater than the acquirement cost. So the game nodes should be convert to the target enterprise's strategic space. When the target enterprise is anti-takeover and the acquirer successfully buy it, the acquirer's earning will be $\mathrm{V} 1-\mathrm{V}^{*}-\mathrm{C}^{*}$, and if the acquirer fails to buy it, the acquirer's earning will be $-\mathrm{C} *$. We can see the gap between acquirer valuation $\mathrm{V} 1$ and the target enterprise valuation $\mathrm{V} *$, namely if the target enterprise think the acquirer valuation $\mathrm{V} 1$ is greater than their own valuation $\mathrm{V} *$, the target enterprise is willing to be acquired, otherwise the target enterprise will choose to be anti-takeover. In the final analysis, whether the last result is (acquisition, cooperation) or (acquisition, non-cooperation) depends on the weighted expected earnings judgment of the acquirer for the posterior probability of the target enterprise. 


\section{Case Analysis}

The period 2014-2015 is the outbreak year of Chinese M\&A. One reason is related to the Chinese economic transformation and upgrading, the second is the further simplification of administrative examination and approval as well as the easing of the policy, and the third is that PE and VC are anxious to make a profit by means of IPO of their enterprises and M\&A by others. The characteristics of the wave of M\&A are respectively as follows: the layout of the Internet giant BAT's ecosystem, traditional industries getting into newly-developing industries by trans-boundary M\&A, the reform of state-owned enterprises promoting them to overall listing and the access to private capital; A-share market staging "barbarians" invasion, listed companies such as Gemdale, Financial Street, Shanghai Xinmei, Changyuan group and New Huangpu being raised many times. Value depression with dispersed ownership is easy to be coveted by M\&A power in the capital market (Wang, Wei, and $\mathrm{Lu}, 2014$ ). What we can expect is that the M\&A value ratio of GDP will gradually rise with the development and further with the opening of Chinese capital market. New ways of M\&A financing and the use of innovative tools will appear in the domestic market in the next decade and will function well. In the following part of this paper, we will take an example of KKR's LBO, which is the most classic leveraged buyout in the history, and analyze the above-mentioned game analysis framework into the application of M\&A.

\subsection{Background of $M \& A$}

The introduction of M\&A: RJR Nabisco, which was merged by the cigarette giant Reynolds and food giant Nabisco, appeared fine and smart, but it had a huge leak in business strategy and corporate culture. In 1988, the company's CEO Ross Johnson decided to sell the company. Although he did not have a majority of company's shares, he tried to persuade the board of directors and made the Wall Street informed of it. He wanted to make it complicated and made profits in it. Johnson wanted the company to be acquired by means of the management layer and made it a private enterprise. It was time when Johnson and the Shearson company had planned it well, the bid of KKR made the management layer come to realize the truth. Finally, KKR won the war with 25 billion dollars, 109 dollars per share, which was called a classic match. This so called "big acquisitions of the century" astonished the world by its 25 billion purchasing price, and became the biggest LBO in the history. This M\&A war was mainly between the senior executives of RJR Nabisco and the famous M\&A company KKR. For its huge scale, some top investment banks and financial institutions such as Morgan Stanley and Credit Suisse First Boston were involved it via direct ways or indirect ways.

Target enterprise:

RJR Nabisco (RJR Nabisco special committee which represents the shareholders will consider the offer and choose whether to accept or not in the end)

M\&A participants:

The first bidder is part of the RJR Nabisco management, American Express Company, Salomon Brothers Company, Shearson - Lehman - Hutton Company and Public Relations Consultant Company:

The second bidder is KKR, Lambert, Morgan Stanley, Walter Seth Pereira Company;

The third bidder is Foster Little Joint Company, Goldman Sachs;

The fourth bidder is First Boston Company.

M\&A process:

On October 19, 1987, RJR Nabisco stock market price was US $\$ 55.875$, and the market value was US $\$ 13.8$ billion. The bidders thought that the target enterprise value was greatly underestimated in the stock market. RJR Nabisco had a very strong and stable cash flow, and it could use more favorable capital structure (high liability) to save tax to improve the target enterprise's value.

KKR and MBO team agreed that RJR Nabisco's existing management strategy had a problem and could not maximize the interests of the shareholders.

1. The development strategy of bidders and the quotation, after the acquisition

(1) bidders

A. On October 20, 1988, the RJR Nabisco management team first sent out MBO takeover offer. Bidders were RJR Nabisco vice chairman Horrigan, investment bank Shearson Lehman Hutton. Offer: US \$75 per share, total purchase price: US $\$ 17$ billion, 34\% higher than the stock market price which was US $\$ 55.875$

B. On October 24, 1988, KKR announced its LBO takeover offer 4 days after the management team announced the MBO offer. Offer: US $\$ 90$, total purchase price: US $\$ 20.7$ billion, $61 \%$ higher than the stock market price which was US $\$ 55.875,20 \%$ higher than the management team offer 
(2) RJR Nabisco set up a special committee considering takeover offer

RJR Nabisco special committee:

Charles E, Hugel, chairman of RJR Nabisco

John d. Macomber, vice chairman of RJR Nabisco

Martin s. Davis, outside director

William s. Anderson, outside director

Albert 1. Butler, Jr., outside director

RJR special committee hires outside consultants

Investment banks

Dillon, Read \& Co.

Lazard Freres, Inc.

Law firms

Skadden, Arps, Slate, Meagher \& Flom

Young, Conaway, Stargatt and Taylor

2. MBO team put forward the company development strategy when bidding

(1) The reason for MBO team acquisition

The stock market underestimated the tobacco business's ability to generate strong cash flow and great market value; Because of the influence of the tobacco business, its food business value was also underestimated by the stock market.

(2) MBO team put forward a new strategy for RJR Nabisco

Sell the food business, RJR Nabisco's CEO, F. Ross Johnson had rich experience in food industry. The food industry was undergoing a massive restructuring at the time. The two big food companies, Pillsbury and Kraf, had become the target enterprises in a series of M\&A wars. Expected sales income: US $\$ 12.5$ billion - US $\$ 15.5$ billion, retaining its tobacco business, transferred it from a listed company to a private company.

(3) MBO team believed that the new strategy could help the RJR Nabisco stock get correct evaluation and generate high returns.

3. The development strategy KKR proposed for target enterprise when bidding

(1) The development strategy KKR proposed for target enterprise was in sharp contrast to the idea of MBO team

(2) RJR Nabisco new strategy proposed by KKR: keeping the integrity of RJR Nabisco's existing business, retaining all the tobacco business, retaining most of the food business, and transforming from the listed company into a private company.

\section{The M\&A process}

(1) The opening

A. KKR signed confidentiality agreement with RJR;

B. KKR did more investigation to know about RJR business operation condition;

C. KKR invited MBO team to buy RJR Nabisco together;

D. On October 26, 1988, because the two parties failed to reach an agreement, KKR gave up the cooperation plan;

E. On November 3, 1988, the second cooperation plan failed;

F. On November 3, 1988, MBO team announced its tender offer after the modification;

G. then the bidders appeared: Forstmann Little \& Co and First Boston Corp combined to be First Boston team which was also considering buying RJR;

H. Forstmann Little team also signed a confidentiality agreement with RJR.

(2) On November 7, 1988, RJR Nabisco special committee set up the rules of the game:

A. The price in the tender offer should reflect the highest offer of potential acquirer;

B. The tender offer should not take the sale of any asset of RJR Nabisco as a prerequisite; 
C. The tender offer should provide RJR Nabisco common stock shareholders with corresponding interests;

D. The tender offer should include the details of financing arrangements, such as access to the cash and how securities make up the non-cash part;

E. The tender offer must be ratified by the board of directors to take effect before it is submitted;

F. The board of directors of RJR Nabisco and special committee reserved the right to modify and terminate the procurement rules, and had the right to terminate the discussion with any bidder and reject any tender offer;

G. All objects should be in before 5:00 PM on November 18, 1988 to submit;

H. To make the M\&A process in order, those offers which did not conform to the requirements of were regarded as hostile takeover.

(3) The main content of the First Boston team tender offer

A. Only buy RJR Nabisco's tobacco business: US $\$ 15.75$ billion in cash, the new company stock warrants: valuated as US $\$ 2$ - US $\$ 3$ per share stock of RJR Nabisco, all stock warrants to buy $20 \%$ of the common stock.

B. Sell the food business of RJR Nabisco at the same time, expected sales income: US \$13 billion, RJR Nabisco existing shareholders would receive the whole cash income from the sale of the food business.

(4) On November 29, 1988, the special committee evaluated the bids at 5:00 PM:

A. First Boston team's bidding was not practical in operation;

B. Decided to negotiate with KKR about the bid conditions and acquisition agreement details.

(5) On November 29, 1988, at 5:00 PM, the comparison between the conditions of KKR and MBO team;

(6) Special committee continued the evaluation on November 30, 1988;

(7) On November 30, 1988, in the evening, special committee invited its financial adviser for final evaluation

A. Special committee recommended the tender offer of KKR to the board of directors of RJR Nabisco;

B. RJR Nabisco signed a purchase agreement with KKR.

(8) The reason why special committee recommended the object to KKR

A. continual negotiations could lead to bidders' exit;

B. KKR object provided more new equity ingredients, KKR: $25 \%$, MBO team: $15 \%$;

C. KKR would retain the tobacco business and most of the food business; While MBO team would only retain the tobacco business;

D. KKR's object contained fewer PIK securities;

E. MBO team's object provided US $\$ 3.00$ more per share than KKR;

F. KKR would provide benefits for RJR employees who were leaving, the MBO team did not provide any benefits;

G. KKR agreed not to do big cut.

5. Questions

(1) How should the acquirer decide on the right price and financing way in bidding?

A. The acquirer should make a comprehensive analysis of the target enterprise including existing strategy, operating plan, financial analysis and enterprise value evaluation.

B. The acquirer should design a better strategic plan in order to improve enterprise's operating efficiency, and forecasts the next 5 to 10 years' operating cash flow.

C. According to the predicted cash flow, the acquirer should design a sound acquisition financing plan, and do enterprise value evaluation using discounted cash flow method.

(2) Why are the enterprise value evaluation results different in different schemes?

A. RJR Nabisco's valuation was much higher than the original plan in either KKR's or MBO's scheme;

B. There were two main reasons: the value promotion results from capital operation or the promotion of enterprise operation efficiency (Gao, 2015).

(3) Analysis and comparison of enterprise value evaluation under different schemes was necessary.

6. In the end, KKR acquired the major decisions after acquisition. 
In March 1989, KKR appointed Gerstner as the new president of RJR Nabisco. On April 28, 1989, KKR formally completed the acquisition of RJR with a deal amount of US \$25 billion.

\subsection{M\&A Game Analysis}

The above case analysis of KKR acquiring RJR Nabisco, made a relatively clear reduction for the classic M\&A incident. It seemed that KKR spent too much (US \$25 billion). But anyone who knew about this event understood that KKR's cost was minimal in the acquisition, because KKR issued a large number of junk bonds for financing, and promised to repay debt by selling acquired company's assets. Although the scale of the purchase money was more than $\$ 25$ billion, the using cash was less than $\$ 2$ billion (KKR used more than 10 times leverage in the LBO M\&A). In the final round of bidding, Hilsen's quotation was only \$1's difference with KKR's, which is $\$ 108$ per share. But what prompt RJR Nabisco's shareholders to make the final decision was not the purchase price's difference. KKR guaranteed to give $25 \%$ of the shares to shareholders, while Hilsen only planned to give $15 \%$ of the shares to shareholders; KKR promised to sell only a small part of RJR Nabisco's business, whereas Hilsen wanted to sell all of the business. In addition, the shareholders list other ten several differences. Hilsen failed to confirm the reliability of its securities by restructuring, and did not enough in terms of employee benefits security. Because of these reasons, the shareholders finally chose KKR.

Engels once said: "the beginning and going on of the revolution will be for the interests rather than principle, and only benefits can develop to be principle." RJR Nabisco shareholders delegation and its management, KKR and other bidders experienced a round of game. Among these stakeholders, the party who could make the banker to get maximum benefit will win, but each party has its own constraints (can provide how much cash to pay for the acquisition, cost-recovering or not at last, etc.) (Mueller and Panunzi, 2004). Obviously KKR was not more familiar with target enterprise than the management, even not than the investment bank. KKR is not dominant in the information, but the clever thing of the game lay in that the game was not just for the cognition of information, more was about the choice of strategy (that is, on the right track). Reviewing the reason why RJR Nabisco chose KKR, we could find that KKR's takeover is the only one which seemed well-meaning (KKR gave more shares and benefits to shareholders), but KKR deeply knew where shareholders game node is (shareholders delegation tended to individual short-term interests, and did not know KKR financing arrangements was actually to make the future cash flow as guarantee to repay the junk bonds, the following development of the target enterprise confirmed this point). KKR used its advantages in strategy to make it to the end. To simplify the case as the following: 
$\mathrm{MBO}$ (Started the acquisition, $34 \%$ premium)

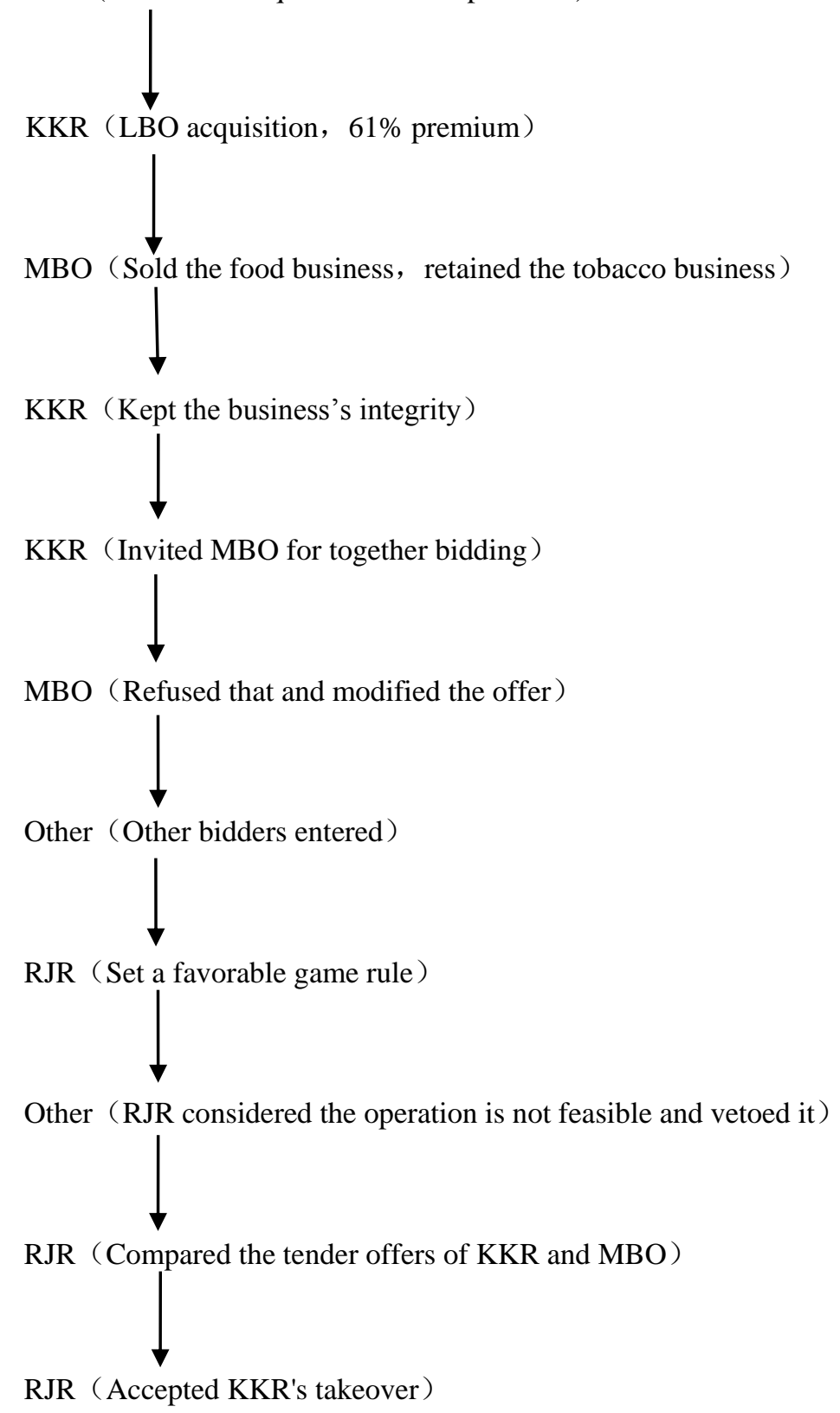

In the above example, MBO refers to the management of M\&A, RJR refers to target enterprise special committee, while Other refers to Other participants. Watch the game process, we find that KKR can always cleverly "gain mastery by striking only after the enemy has struck", suppressing the most important enemy MBO team. I guess KKR knew "the rules of the game" set by RJR Nabisco special committee from the start of the game. KKR's every step is to make this node quickly realized.

Compare KKR acquiring target enterprise in Figure 4 with management MBO acquiring target enterprise in Figure 5, the game ideas of the case is evident. KKR and MBO group both gave RJR Nabisco high premiums. But MBO was always passive in the game, in the beginning, $\mathrm{MBO}$ team's game track was the path of $\mathrm{X} 0 \rightarrow \mathrm{X} 2 \rightarrow \mathrm{X} 5$ path. If there were no third party such as KKR appearing, MBO management team would have used a small price to $\zeta 0+\mathrm{C}$ to buy RJR Nabisco, but only four days after the bid, KKR immediately joined the bidding (figure 4). KKR's game track was $\mathrm{X} 0 \rightarrow \mathrm{X} 1 \rightarrow \mathrm{X} 3$. KKR gave $61 \%$ overflow offer, which is higher than MBO group's $34 \%$ overflow. MBO team was forced to modify the offer, which meant the game path $\mathrm{X} 0 \rightarrow \mathrm{X} 2$ was amended as $\mathrm{X} 0 \rightarrow \mathrm{X} 1$. Then the RJR special committee faced the same path of KKR and MBO team, RJR set a "game rules" before ruling:

(1) Price in the tender offer should reflect the potential acquirers' highest bid;

(2) The tender offer should not take the sale of RJR Nabisco's any asset as a prerequisite; 
(3) The tender offer should provide RJR Nabisco common stock shareholders with fair interests;

(4) The tender offer should include details of the financing arrangements, such as the arrangement of access to the cash and how non-cash part will be made up with securities;

(5) The tender offer must be ratified by the board of directors before being submitted by the bidders;

(6) RJR Nabisco's director board and special committee reserve the right to modify and terminate the auction rules, and have the right to terminate the discussion with any bidder and reject any bid;

(7) All objects should be submitted before 5:00 PM on November 18, 1988;

(8) To guarantee the takeover bid to proceed in an orderly way, the tender offer that does not meet the requirement will be regarded as hostile takeover.

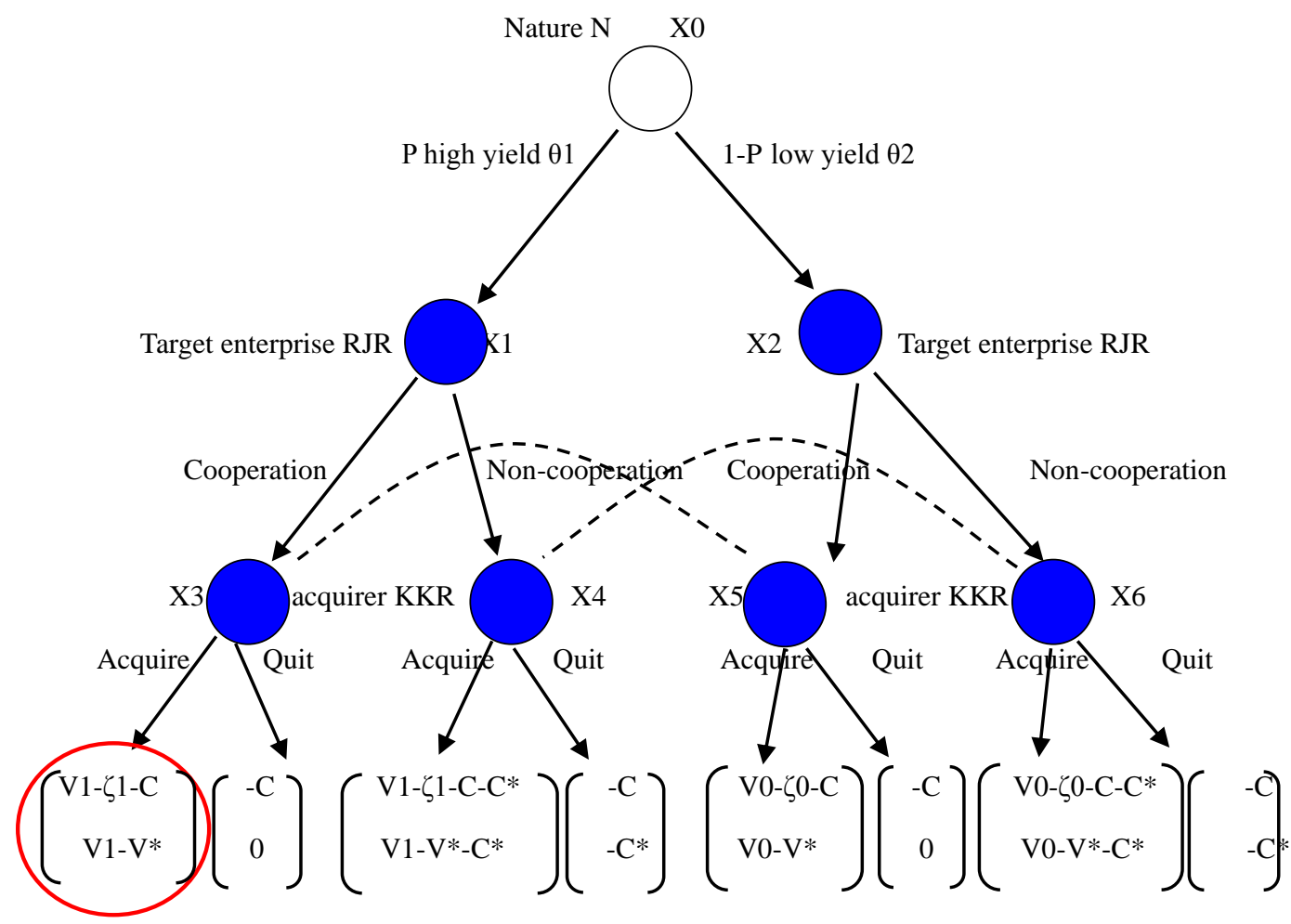

Figure 4. KKR Acquiring RJR Nabisco

Checking the above item by item, we will find that for the first item, KKR and MBO team were finally close (\$109 to $\$ 108$ ). For the second item, we can review strategies comparison after the acquisition in the case, KKR put forward that the business integrity should be preserved in the tender offer, MBO team planned to sell the food business (this point is very delicate, because what KKR used was LBO tactics. The target enterprise would be insolvency as long as its performance was less than expected. Then not only the food business would be sold, maybe the whole company would be on the verge of bankruptcy risk). At this point, KKR was essentially not better than MBO group, but KKR was clever to hide the information that was negative to itself (that is, the company will face huge risk in the future), and then participated in the game. For the third item, KKR could not give shareholders more cash than MBO management team, but KKR avoided the node against it again, KKR sacrificed part of the shares to benefit RJR shareholders. For no layoffs after acquirement and the promise of welfare to leaving employees, these are all used to tempt RJR committee to change MBO team's game path from the $\mathrm{X} 1 \rightarrow \mathrm{X} 3$ to $\mathrm{X} 1 \rightarrow \mathrm{X} 4$. At the last minute, it is expected that KKR's tender offer was favored. As a result, what KKR faced was the payoff in red circle in figure 4, namely, KKR's profit was V1- $\zeta 1-C$. MBO team will exit, what it faced was the payoff in red circle in figure 5, namely, the sunk cost $-\mathrm{C}$. The comprehensive income of RJR original shareholders was $\mathrm{V} 1-\mathrm{V}^{*}-\mathrm{C}^{*}$. 


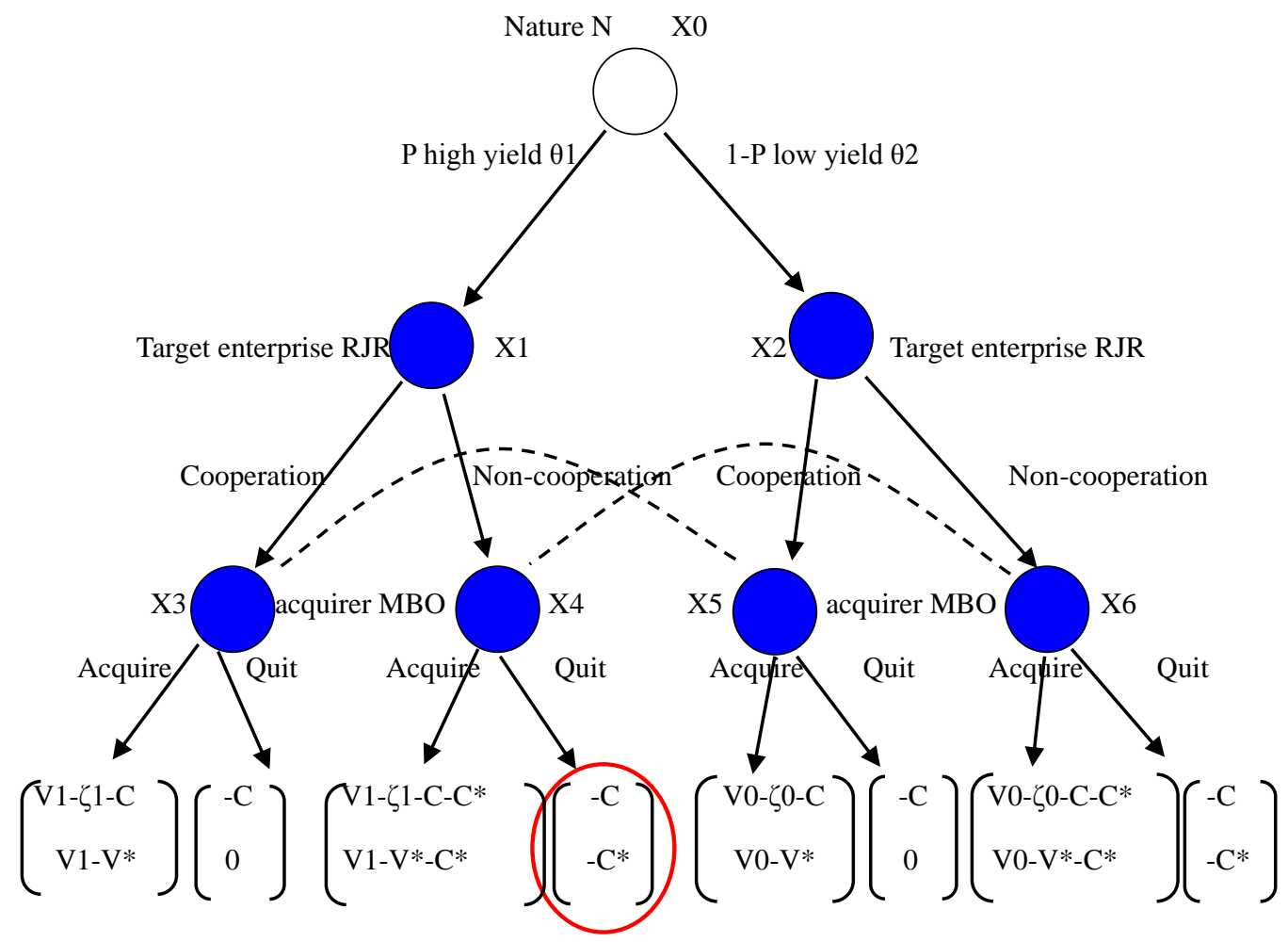

\section{Concluding Remarks}

Figure 5. MBO Acquiring RJR Nabisco

The game theory developed human thinking. If the game theory is arbitrarily misused as a kind of "brilliant" tool, some subject areas will be filled with some far-fetched things. This is well worth maintaining vigilance. In this paper, combining with the hot topic of present economic transition, with the breakthrough point of enterprises M\&A to optimize allocation of resources, we use the dynamic game under incomplete information research to do M\&A research. This article uses classic case to explain the game logic framework. The structure is clear. There are innovations in thinking methods. One is the further development of strategy application for stakeholders in the process of game. The second is the expansion of the research scope in the study of game theory in enterprise M\&A, which is more closed to the practice of real society. After all, limited to the understanding of all information in the case and the mastery degree of game tools, empirical research of this article remains to be further improved. In addition, it is necessary to further improve the methods in other cases (especially the M\&A cases of state-owned enterprises in the reform process).

\section{References}

Andrade, G., Mitchell, M., \& Stafford, E. (2001). New evidence and perspectives on mergers. Journal of Economic Perspectives, 15(2), 103-120. http://dx.doi.org/10.1257/jep.15.2.103

Binmore, K., Ariel, R., \& Wolinsky, A. (1986). The Nash bargaining solution in economic modeling. Rand Journal of economics, 17(2), 176-188. http://dx.doi.org/10.2307/2555382

Cao, Y., \& Yang, Z. (2005). The analysis of acquisition and merger based on signaling game model. Nankai Business Review, 8(4), 39-43.

Fang, H. (2002). A bargain model: the application in the price negotiations on enterprise acquisition and merger. Academic Exchanges, 18(6), 52-53.

Gan, C. (2005). The essence of the merger and acquisition cases. Shanghai, SH: Fudan University Press.

Gao, Z. (2015). The enterprise merger and acquisition effect on firm value-a discussion on Geely's acquisition of Volvo for example. Modern Economy, 6(6), 717-726. http://dx.doi.org/10.4236/me.2015.66068

Hong, Y. (2001). Shared interest theory. Shanghai, SH: Shanghai People's Press.

Jarrell, G., \& Poulsen, A. (1989). The returns to acquiring firms in tender offers evidence from three decades. Financial Management, 18(3), 12-19. http://dx.doi.org/10.2307/3665645

Leland, H. (2007). Financial, synergies and the optimal scope of the firm: implications for mergers, spinoffs, and 
structured finance. Journal of Finance, 62(2), 765-807. http://dx.doi.org/10.1111/j.1540-6261.2007.01223.x

Mueller, H., \& Panunzi, F. (2004). Tender offers and leverage. Quarterly Journal of Economics, 119(4), 1217-1248. http://dx.doi.org/10.1162/0033553042476198

Nogeste, K. (2010). Understanding mergers and acquisitions (M\&As) from a program management perspective. International Journal of Managing Projects in Business, 3(1), 111-138. http://dx.doi.org/10.1108/17538371011014053

Perry, M. K., \& Porter, R. H. (1985). Ology and the incentives for horizontal merger. American Economic Review, 75(1), 219-227.

Smit, B. T., \& Akum, L. A. (1993). A real options and game-theoretic approach to corporate investment strategy under competition. Financial Management, 2(3), 241-250. http://dx.doi.org/10.2307/3665941

Stigler, G. J. (1996). Industrial organization and government regulation. Shanghai, SH: Shanghai People's Press.

Wang, S., Wei, J., \& Lu, Y. (2014). The impact of absorptive capacity on technological performance in transnational technology M \& As based on evolutionary game theory. Studies in Science of Science, 32(12), 1828-1835.

Zhang, W. (1996). The game theory and information economics. Shanghai, SH: Shanghai People's Press.

\section{(c) E EY}

This work is licensed under a Creative Commons Attribution 3.0 License. 